Departamento de Química Orgânica e Biológica

Diretor: Prof. Dr. Fonseca Ribeiro

\title{
AÇÃO DA HIPÓFISE DE PEIXE SÔBRE O OVIDUTO DO SAPO, BUFO MARINUS (L.)
}

\author{
Fonseca Ribeiro e J. F. Tabarelli Neto \\ (Assistente) \\ 2 estampas (3 figuras)
}

Em 1938, Allende (1), querendo comprovar, se no sapo Bufo arenarum Hensel, a ação da hipófise sôbre o aparelho sexual era, do mesmo modo que nos mamíferos, indiréta, idealizou, por motivos que logo mais exporemos, uma técnica mui sugestiva, agora por nós usada no estudo da ação da hipófise de peixe no sapo.

Como sabemos, nestes animais, os óvulos saem ao exterior formando uma larga cadeia cujo elemento de união é uma substância gelatinósa secretada pelas glândulas do "oviduto". A implantação hipofisária por conseguinte, além de provocar a libertação dos óvulos, estimula a atividade secretora destas últimas. Ainda segundo ALLENDE (1-2), o que se designa nos batraquios anouros pelo nome de “oviduto", só em parte corresponde ao conduto homônimo dos mamíferos. Com efeito, tanto estrutural como funcionalmente, é só a chamada "parte réta" do mesmo, (equivalente apenas a $5 \%$ da longitude total) a que corresponde ao oviduto daqueles. O resto constitue um órgão nìtidamente glandular destinado a munir o óvulo da substância gelatinosa já mencionada, que os une entre si em cadeias e que contribue a reforçar suas reservas nutritivas, constituindo mesmo o primeiro alimento da larva. Esta atividade lhe confére um significado funcional talvez semelhante ao das glândulas secretoras do leite dos mamíferos e a do leite do papo (engluvia) de certas aves, como no pombo notadamente. Nestes animais, portanto, o índice mais seguro da atividade funcional do oviduto, está representado pela descarga da substância gelatinósa, elaborada pelas suas glândulas.

Uma vez que as variações sofridas pelo oviduto, na espessura, côr e vascularisação das suas paredes são pouco notaveis e que o quadro histológico do órgão em repouso e em atividade, pelo menos com as técnicas habituais de coloração, não oferece contrastes nítidos, o referido índice foi conseguido por ALLENDE, da forma a mais satisfatoria, incluindo entre duas ligaduras uma porção do oviduto, antes de injetar a substância cuja influência sôbre o órgão se deseja investigar. Nos casos positivos, o segmento bloqueado sofre uma distensão e entumescimento manifestos, como resultado da acumulação dos produtos secretados. Si a ação fôr nula, êles não se manifestam: num ou noutro 
caso isolado, aparece um léve entumescimento em comparação com o oviduto não ligado, porém, o conteúdo evidentemente escasso em comparação com o dos casos positivos é completamente aquoso e não gelatinoso como êstes. A prova é decisiva e não deixa dúvidas. Os resultados podem ser lidos 24 horas após a implantação.

Foram positivos os resultados obtidos por ALLENDE sôbre o oviduto do Bufo arenarum Hensel, não sòmente pela homoimplantação da hipófise (1), como pela injeção de prolactina (3). Êste segundo trabalho foi levado a efeito afim de comprovar se a secreção do oviduto, a cujo significado funcional já nos referimos, estava sob o controle hipofisário anterior, do mesmo modo que as secreções lacteas e a do papo das aves.

Em 1937, Leblond e Noble (4) conseguem resultados positivos por meio de implantações intradérmicas de hipófises de mamíferos, áves, répteis, amfíbios e peixes, na péle que cobre por fora, o papo dos pombos. Porém, duvidam que a reação observada seja específica e que signifique a presença do hormônio lactogênico, pois que o mesmo resultado foi obtido pela implantação de fígado de pombo, tartaruga, peixes ou de cérebros de peixes e, além do mais, não apareceram gôtas de gordura na zona proliferada após coloração com vermelho escarlate.

Em 1940, Foglia (5) verifica que o lóbo anterior da hipófise do sapo, Bufo arenarum Hensel, produz um discréto espêssamento do papo do pombo, em injeção intradérmica, e, admite ser específica a reação pois não a observou com dóses muito maiores de fígado, rins ou músculos de sapo.

Devido ao exposto, ocorreu-nos a idéia de verificar a ação da hipófise de peixe, material com o qual trabalhamos atualmente, sôbre o oviduto do sapo, Bufo marinus (L.).

\section{MÉTODO E MATERIAL}

Como já frizamos foi usado o método descrito por Allende, a qual contudo, não descreve no seu trabalho, a técnica operatória utilizada.

Anestesiavamos o sapo, colocando-o dentro de uma campânula de vidiro, no interior da qual encontrava-se algodão embebido no éter. Uma vez anestesiado e fixado o animal em decúbito ventral, localisavamos o oviduto por meio de uma incisão, de dois centímetros aproximadamente, feita na região lombar, paralela e junta a coluna vertebral. Depois de realizadas as ligaduras do oviduto em dois pontos, de maneira a bloquear um segmento de cerca de 5-8 centímetros, fechavamos o córte suturando a camada muscular e a péle separadamente. Em 
seguida injetavamos uma suspensão aquosa de hipófise pela via subcutânea, após o que, era o animal conservado, na temperatura do laboratório, dentro de uma campânula de vidro, tendo no seu interior um pouco dágua.

O material por nós utilisado constou de hipófises de Prochilodus hartii, (Curimbatá 오), coletadas em Pirassununga, durante a "piracema" de 1942 e conservadas em álcool absoluto. Uma vez enxutas e pesadas, eram as hipófises trituradas em água distilada, e a suspensão assim feita, injetada no animal. Após 24 horas, era o animal sacrificado afím de se fazer a leitura da prova.

Expômos a seguir no quadro abaixo, os resultados por nós obtidos :

\begin{tabular}{|c|c|c|c|c|c|c|}
\hline Sapo & Peso & $\begin{array}{l}\text { N. de } \\
\text { hipófises } \\
\text { injetadas }\end{array}$ & $\begin{array}{l}\text { Pêso em mg } \\
\text { de hipófise } \\
\text { injetada }\end{array}$ & Resultado & \multicolumn{2}{|c|}{$\begin{array}{l}\text { Estado dos } \\
\text { ovários }\end{array}$} \\
\hline 1 & 89 grs. & 1 & 8.0 & 一 & pequenos & (1) \\
\hline 2 & $105 "$ & 3 & 17.3 & - & $"$ & $"$ \\
\hline 3 & $125 "$ & 6 & 34.5 & - & $"$ & $"$ \\
\hline 4 & $174 "$ & 10 & 53.6 & + & grandes & $"$ \\
\hline 5 & 215 & 10 & 45.0 & + & $"$ & $"$ \\
\hline 6 & 90 & 1 & 9.0 & frac. pos. (2) & $"$ & $"$ \\
\hline 7 & 95 & 5 & 35.0 & + & $"$ & $"$ \\
\hline 8 & $142 "$ & 10 & 51.0 & + & $"$ & $"$ \\
\hline
\end{tabular}

(1) Na presente época do ano (Novembro-Dezembro) a maioria dos nossos sapos já desovou, e năo é, sem dificuldade que se consegue exemplares, ainda ótimos para as experiêneias. Ao nos referirmos acima "ovários pequenos" queremos dizer, que pelo estado dos mesmos, o animal já havia desovado, ao passo que nos animais que reagiram positivamente o fenômeno ainda não se havia desovado, ao passo que nos animais que reagiram positivamente o fenômeno ainda não se
havia dado. Notamos mesmo num deles (sapo 7), depois da prova, não só óvulos esparsos pela cavidade abdominal, como também insinuados no oviduto.

$(2)=$ fracamente positivo.

Ẽstes resultados por nós obtidos poderiam ser devidos aos principios gônados estimulantes ou talvez pela presença de prolatina na hipófise do peixe.

Trabalhando, porém, mais tarde, com um extrato glicerinado de hipófise de peixe, por nós preparado, e que provocára a desóva neste último animal, injetamo-lo no sapo, utilisando a mesma técnica anterior. Foram negativos os resultados, porém, não teceremos comentarios a respeito, por ser pequeno o número de provas levado a efeito (3), devido as dificuldades em se conseguir sapos em condições ótimas para a experiência. Esperamos, contudo, poder esclarecer, logo mais, esta questão.

Quanto a desóva do sapo, pròpriamente dita, pela implantação de hipófise de peixe, encontra-se na literatura o trabalho de Houssay, GiUsti e LASCANo GonZÁLES feito em 1929 (6), aliás com resultados 
negativos, técnica que também desejamos repetir, assim que o nosso sapo se encontre em condições para isso, provavelmente depois do mês de Fevereiro.

\section{RESUMO}

Adotando a técnica de ALLENDE, os autores observaram que a injeção de 5 hipófises de peixe, Prochilodus hartii, (Curimbatá $\subsetneq$ ), determina sempre uma reação positiva na sapo fêmea, Bufo marinus (L.), embora em quantidades menores de órgão - até uma hipófise (peso $9 \mathrm{mg}$ ) - já seja observado um efeito de pequena monta; parece ser necessário, para o resultado positivo, que o sapo não tenha desovado recentemente.

\section{ABSTRACT}

Using the Allende's technique, the A. A. observed that the injection of 5 fish hypophyses, Prochilodus hartii, (Curimbatá ㅇ), determines always a positive reaction in the female toad, (Bufo marinus (L.), although in a smaller quantity of the organ - down to one hypophyse $(9 \mathrm{mg})$ - a slight effect may be observed; it seems necessary, for positive result, that the toad has not recently spawned.

\section{BIBLIOGRAFIA}

1 - Allende, I. C. de - 1938 - Influencia directa da la hipófisis sobre el oviducto de los batracios. Rev. Soc. Arg. Biol., 14 (8) : 505-8.

2 - Allende, I. C. de - 1938 - Ciclo sexual del "Bufo arenarum" hembra. Rev. Soc. Arg. Biol., 14 (8) : 515-22.

3 - Allende, I. C. de - 1939 - Acción de la prolactina sobre el oviducto de los batracios. Rev. Soc. Arg. Biol., 15 190-3.

4 - Leblon, C. P. and Noble, G. K. - 1937 - rrolactin-like reaction produced by hypophysis of various vertebrates. Proc. Soc. Exp. Biol. Med., 36: $517-18$

5 - Foglia, V. G. - 1940 - Acción de la hipófises del sapo "Bufo arenarum", Hensel, sobre el buche de la paloma. Rev. Soc. Arg. Biol., 16 (8) : 559-62.

6 - Houssay, B. A., - Giusti, L. y Lascano GonzÁles, J. M. - 1929 - Implantación de la hipófisis y estimulacion sexual en el sapo. Rev. Soc. Arg. Biol., 5: 397-418.

7 - Martins, T. - 1936 - Glandulas sexuais e hypophyse anterior. (Tratado de endocrinologia. Physiologia. Aplicações médicas). São Paulo, Companhia Editora Nacional. 
F. Ribeiro e J. F. Tabarelli Neto,

A şão da hipóf. de peixe sobre o oviduto do sapo
Rev. Fae, Med. Vet. S. Paulo, Vol, 2, fasc, s

Estampa I
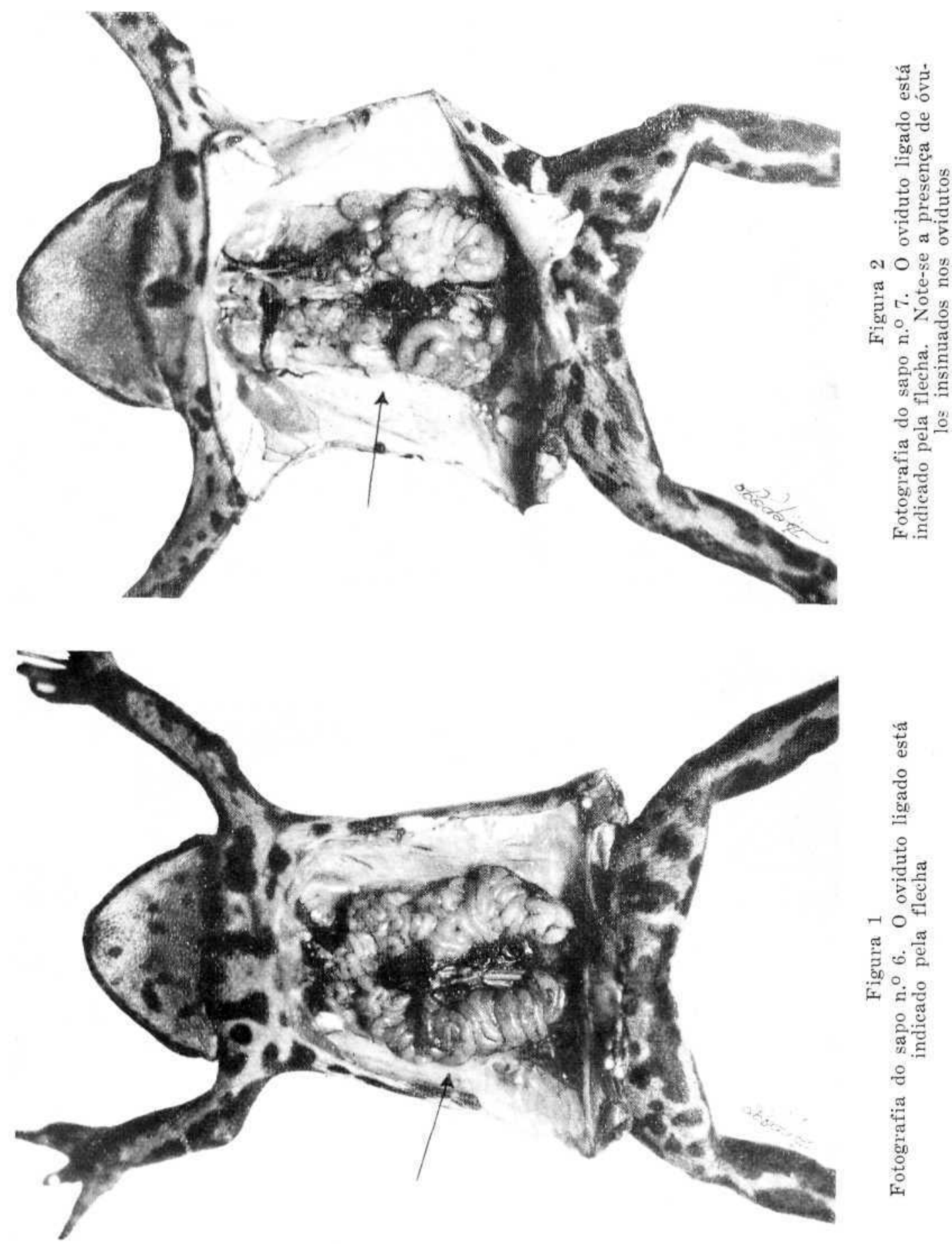

t)

롱

$-0^{4}$

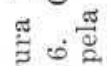

$\stackrel{5}{\circ} 0$

․ㅠㅁำ

응

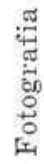




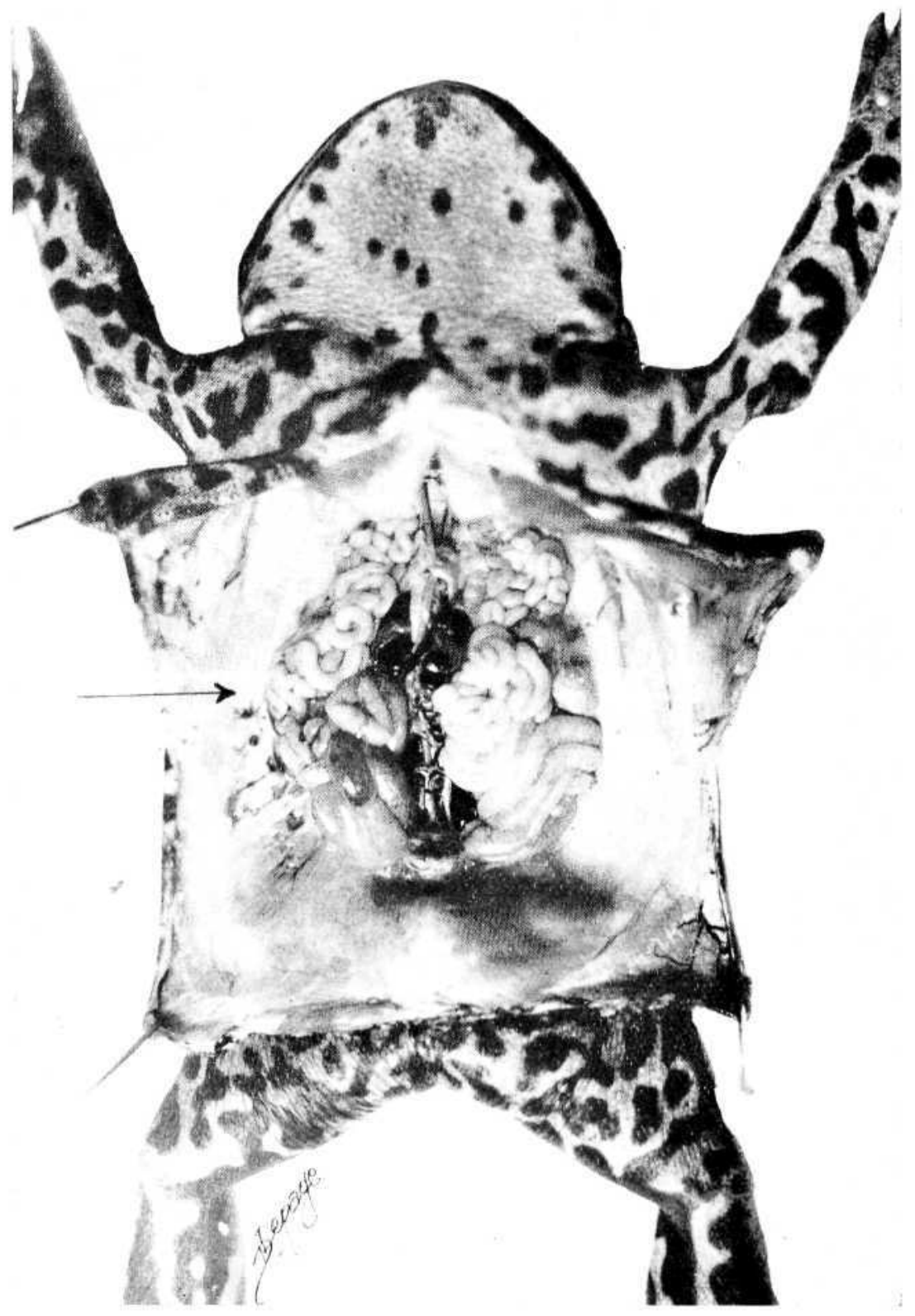

Figura :3

Fotografia do sapo n. ${ }^{\circ}$. 0 oviduto ligado está indicado pela flecha 